\title{
Dynamic Characterization of Short Duration Stress Pulses Generated by a Magnetic Flyer Plate in Carbon-Fiber/Epoxy Laminates
}

\author{
GFPIVEO \\ H.A. Bruck \\ J.S. Epstein \\ K.E. Perry, Jr. \\ OCT 271995 \\ Idaho National Engineering Laboratory \\ OSTI \\ Mohammed G. Abdallah \\ P.O. Box 1625 \\ Idaho Falls, Idaho, 83415-2218 \\ Hercules, Inc. \\ Materials Division \\ Composite Products Group \\ Magna, UT 84044-0098
}

\begin{abstract}
$A b=t r a c t$
There is a great deal of interest in characterizing the dynamic mechanical behavior of laminated carbon-fiber/epoxy composites for military and aerospace applications. Current research efforts have been directed at measuring the strength lost because of accumulated damage. Very little work has been done to determine how this damage is accumulated during dynamic mechanical loading. of particular interest is the effect of short duration $(<1 \mu s)$ stress pulses on mechanical behavior such as delamination. In this paper, a magnetic flyer plate apparatus is presented for generating a short duration stress pulse in a unidirectional carbonfiber/epoxy laminated composite. The stress pulse is charactertzed using a dynamic moire interferometer.
\end{abstract}

\section{Experimental Procedure}

A system was designed for generating short duration mechanical pulses using a magnetic flyer plate (see Figure 1) [1]. The magnettc flyer plate consisted of a $0.254 \mathrm{~mm}$ thick, $6.25 \mathrm{~mm}$ wide strip of aluminum. A current was passed through the strip in one direction, then passed behind it in the opposite direction to generate the opposing magnetic flelds that accelerated the plate. The current was dumped from an $18 \mu \mathrm{F}$ storage capacitor at $10 \mathrm{kV}$ using a spark gap. To determine the veloctty of the flyer plate, shorting pins were placed at several locations along the flight path of the flyer plate and the time to impact was measured at several voltages. From these velocity measurements (Figure 2) it was found that the velocity profiles were consistent between capacitor shots for a given voltage and the plate remained almost flat while in flight.

To Image the short duration stress pulse generated by the magnetic flyer plate, a dynamic moire interferometer was used (see Figure 3) [2]. The interferometer measured the full-fleld displacements on the surface of a specimen in the direction that the stress wave propagated. A pulse ruby laser was used in the interferometer capable of generating high-intensity pulses lasting for a hundred nanoseconds. Molré fringe patterns were captured on high-speed infrared and Polaroid fllm. Because of the sensittvity of the infrared film and the intensity of the ruby laser, neutral density filters had to be used to prevent saturation.

Gratings were placed on the front and back surfaces of specimens. A special 1200 line $/ \mathrm{mm}$ dual frequency grating was used on the front of the spectmen so that a helium-neon laser could be used to align the interferometer. On the back, a regular 300 inne $/ \mathrm{mm}$ grating was used for a diffraction gage. The diffraction gage consisted of a $2 \mathrm{~mm}$ diameter He-Ne laser beam with a fiber optic seasor placed approxtmately 1 meter from the specimen and aligned along the first diffraction order of the grating. By placing the sensor at an appropriate distance from the specimen, the diffraction gage was able to detect the exact time that a stress wave passed a given location along the length of the specimen from the deflection of the laser beam. These data could then be used to determine the proper trigger time for the ruby laser.

\section{Experimental Results}

A short duration stress pulse was characterized for a $0^{\circ}$ unidirectional carbon-fiber/epoxy specimen (see Figure 4). The specimen was $4.5 \mathrm{~mm}$ thick, $11.7 \mathrm{~mm}$ wide, and $150 \mathrm{~mm}$ long. The end of the specimen was placed $7 \mathrm{~mm}$ from the flyer plate, which resulted in an impact velocity of approximately $175 \mathrm{~m} / \mathrm{sec}$. The moire interferometer covered $42 \mathrm{~mm}$ of the specimen, starting at a location $35 \mathrm{~mm}$ from the impacted end of the specimen. The diffraction gage was positioned at the edge of the grating closest to the impacted spectmen end.

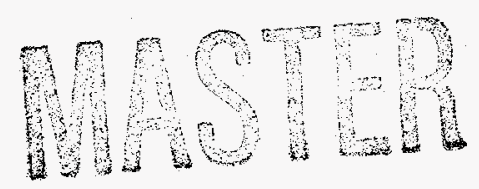


During the course of the experiment, it was determined that extraneous light generated from the current being discharged through the magnetic flyer plate was saturating the optical sensor of the diffraction gage and the film used to capture the moiré images. Consequently, interference fllters had to be used to eliminate this problem.

The stress pulse captured in the experiment had a slightly bowed wave front (see Figure 5). This probably indicates that the flyer plate is slightly bowed when it impacts the specimen. The stress pulse was approximately $3 \mathrm{~mm}$ in length. To calculate the duration of the stress pulse it was necessary to estimate its wave speed. The longitudinal wave speed, $c_{L}$, for the $0^{\circ}$ direction in a carbon-fiber/epoxy laminated composite has been measured to be $8 \mathrm{~mm} / \mu \mathrm{s}$ [3]. For an infinite plate of finite thickness, the effects of dispersion result in a phase velocity of approximately $0.56 c_{L}$ for a pulse length of $3 \mathrm{~mm}$ and a plate thickness of $4.5 \mathrm{~mm}$ [4]. Thus, the corresponding pertod of the stress pulse can be estimated as 700 ns. In addition, there is a substantial wake behind the stress pulse.

\section{Future Work}

The short duration stress pulse generated by a magnetic flyer plate has been characterized in a unidirectional carbon-fiber/epoxy composite. Efforts are currently underway to examine the interaction of short duration stress pulses with delaminations in $0 / 90^{\circ}$ carbon/fiber epoxy composites. Multiple interferograms will be obtained using a high speed framing camera. From these interferograms, crack tip opening and sliding displacements will be extracted. Specimens will also be subjected to various loading rates and input energies by controlling the flyer plate velocity. The behavior of delaminations can then be characterized as a function of pulse magnitude and duration.

\section{Acknowledgment:}

This work is supported by the U.S. Department of Energy, Office of Energy Research, Office of Basic Energy Sclences, Dr. O.A. Manley program manager under DOE Contract No. DE-AC07-94ID13223. Specimens were supplied by Hercules Advanced Materials Co. through their internal and development funding. The technical assistance of Mr. Jim Lee is also gratefully acknowledged.

\section{References}

[1] Jacobson, R.S., "Magnetic Acceleration of Flyer Plates for Shock Wave Testing of Materials", Sandia Corp., Livermore, CA, Sept. 1967.

[2] Epstein, J.S., Deason, V.A., and Abdallah, M.G., "Impact Wave Propagation in a Thick Composite Plate Using Dynamic Moiré Interferometry", Optics and Lasers in Engineering, vol. 17, pp. 35-46, 1992.
[3] Pearson, L.H., Murri, W.J., and Gardiner, D.S., "Ultrasonic Detection of In-plane Properties of Composite Laminates", Proceedings of IEEE 1985 Ultrasonics Symposium, ed. by B.R. McAvoy, vol. 2, pp. 983-989, 1985.

[4] Kolsky, H., Stress Waves in Solids, Dover Publications, New York, 1963. 


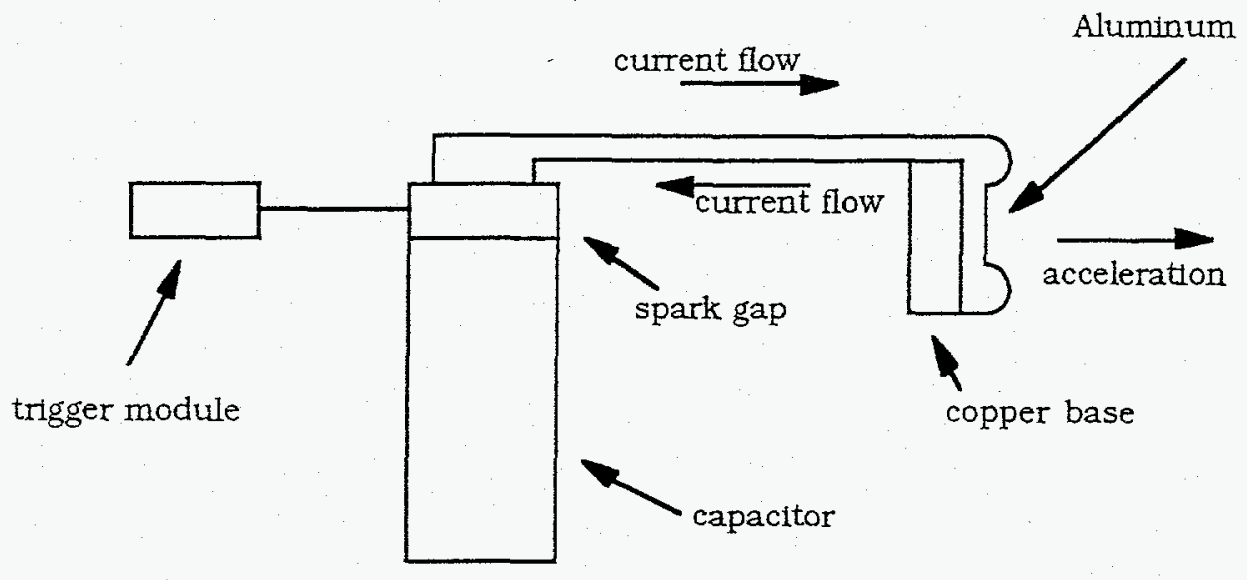

Figure 1: Magnetic flyer plate apparatus.

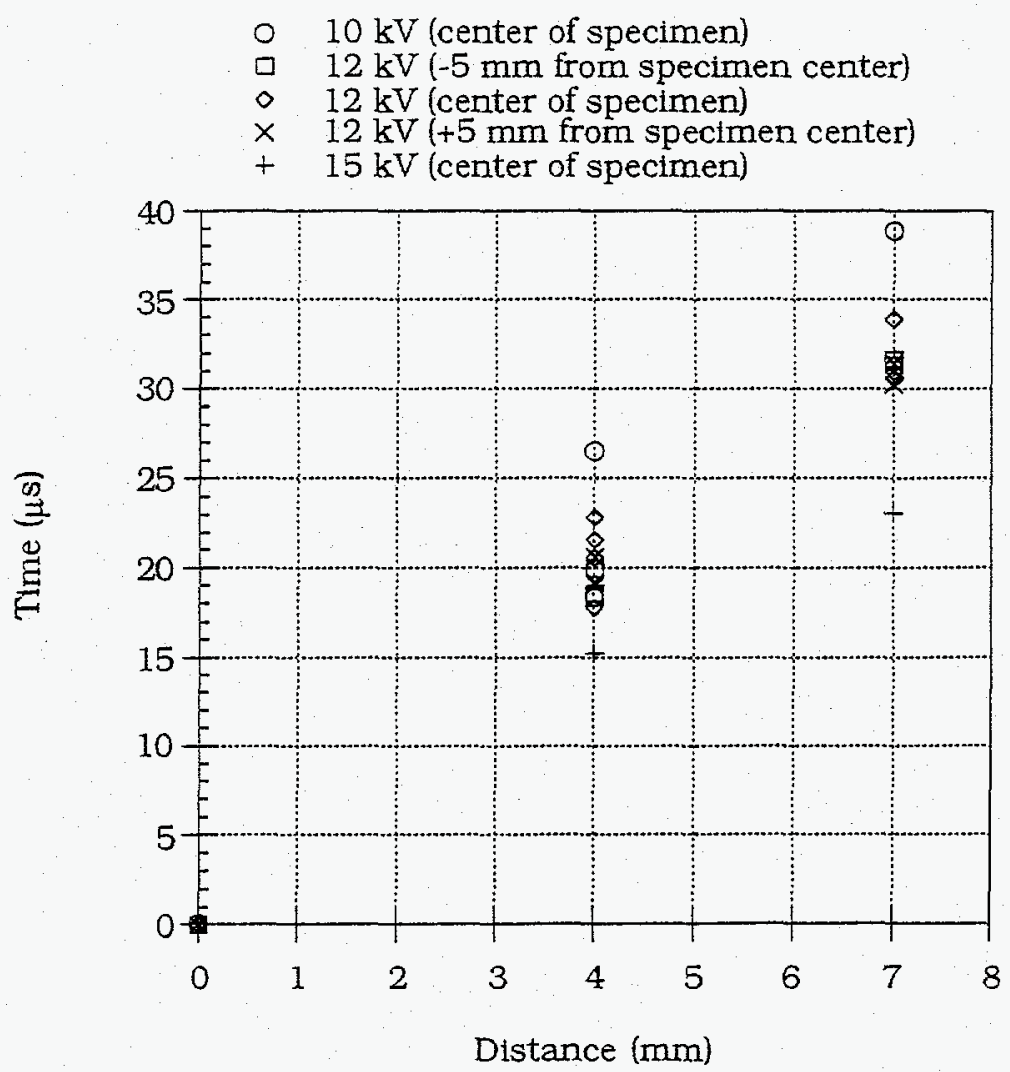

Figure 2: Veloctty measurement data using shorting pins 


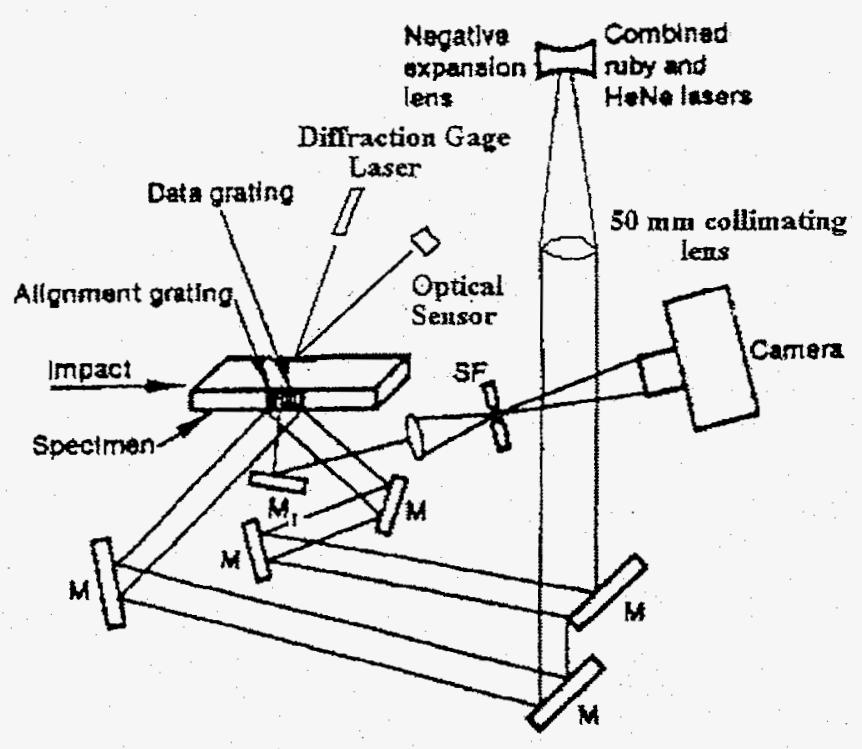

Flgure 3: Dynamic moiré interferometer setup

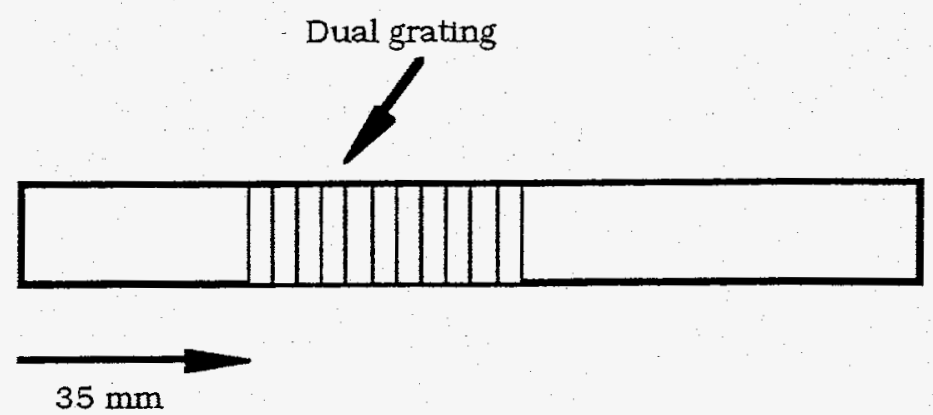

Figure 4: Location of dual grating on carbon-fiber/epoxy specimen. 
Direction of wave propagation

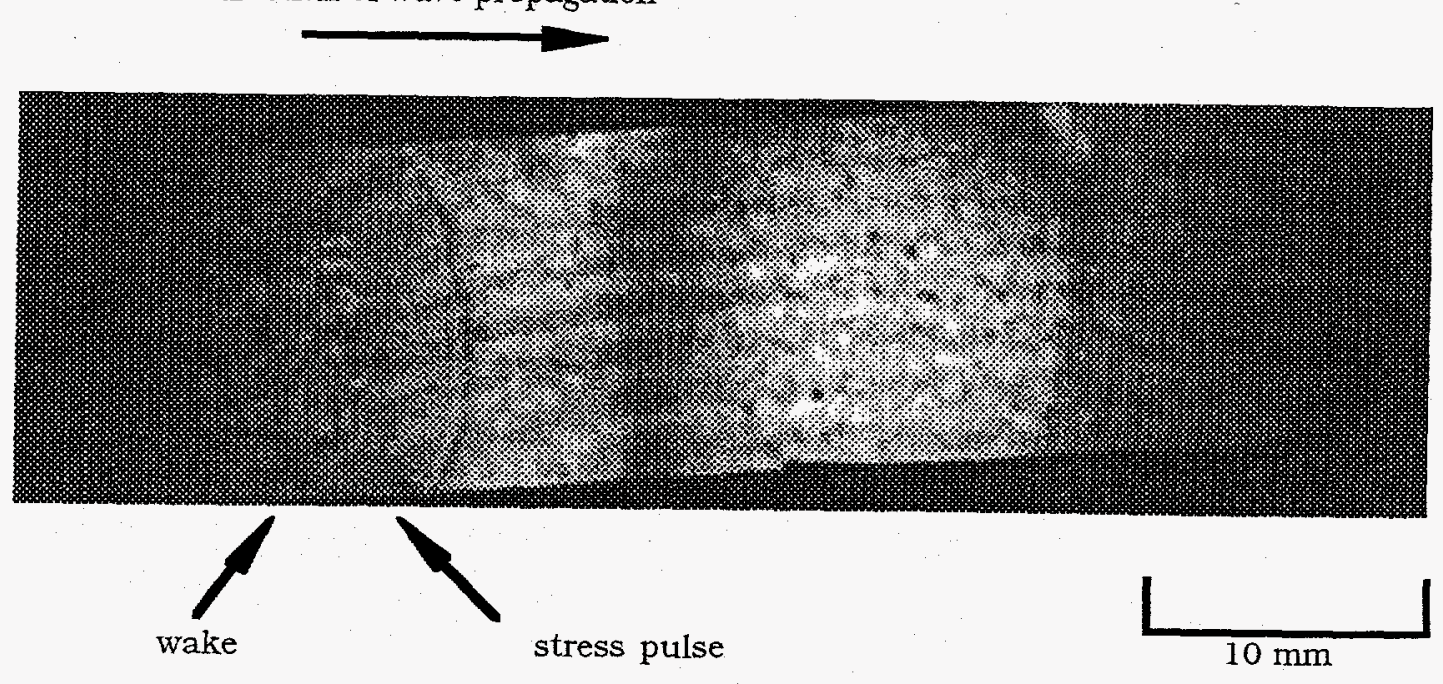

Figure 5: Short duration stress pulse captured in unidirectional $0^{\circ}$ carbon-fiber/epoxy laminated composite.

\section{DISCLAIMER}

This report was prepared as an account of work sponsored by an agency of the United States Government. Neither the United States Government nor any agency thereof, nor any of their employees, makes any warranty, express or implied, or assumes any legal liability or responsibility for the accuracy, completeness, or usefulness of any information, apparatus, product, or process disclosed, or represents that its use would not infringe privately owned rights. Reference herein to any specific commercial product, process, or service by trade name, trademark, manufacturer, or otherwise does not necessarily constitute or imply its endorsement, recommendation, or favoring by the United States Government or any agency thereof. The views and opinions of authors expressed herein do not necessarily state or reflect those of the United States Government or any agency thereof. 